\title{
Analysis on the Development Pattern of Lodge Tourism
}

\author{
Zhiliang Xia \\ Wenzhou Vocational \& Technical College, Wenzhou, 325035 \\ Xia441@sina.com
}

Keywords: lodge tourism, characteristics, development pattern

\begin{abstract}
This paper intends to summarize a development pattern of cultural heritage development-oriented block tourism. By using the space structure of the block and the historical and cultural research values possessed by some distinctive buildings and the remaining cultural resources, the tangible material heritage and intangible heritage will be used as the core elements for the attraction of tourism development. The author believes that, the tourism development cannot purely focus on economic benefits, but needs to coordinate the relations between protection and development and ensure the sustainable development of block tourism.
\end{abstract}

\section{Background}

The pattern of tourism development in historical and cultural blocks generally can be divided into "the use of cultural heritage", "recovery of the memory for block", "commercial format upgrading", "vacation space construction", "scenic service extension", "characteristic industry agglomeration", "cultural theme deduction" and "urban cultural character molding".

According to the planning and deployment as well as the characteristics of tourism resources, development and operation model and industry scale, the process of tourism development and tourism modalities can be designed, the tourism products that are not conducive to heritage protection and tourism development can be abandoned, and the products which can coordinate with the block ecology, and reasonably control the tourism products and environmental indicators can be designed. Given the block and the development of local economic industry, a development and management model suitable for the development and cultural protection can be chosen, which is one of the key factors to determine the success of the block tourism development. In view of the large size of such blocks and their prominent independence, they can be tied to the city brand to shape their own independent brand.

From the perspective of tourism products, different tourism products with various cultural heritage resources as a transformation method can be designed, the systematic tourism products system can be constructed. The transformation mode for historical block heritages is shown in table 1 .

The development of the block cultural heritage needs to choose a suitable brand shaping way, and formulate the long-term brand marketing strategy, which will be advantageous to the block tourism quality promotion and continuously enhance the block market's influence, attract the more support and the attention for the block development and the protection. The building of a continuous operation system is not only the need for the development of the block tourism, but also 
the need for the protection of the cultural heritage. From the planning aspect, it needs to consider the income model of block tourism, determine the proportion of tourism income that needs to be used for district management, infrastructure construction, cultural protection and residents' rehousing, and needs to design the participation ways and rearrangements of local residents, properly handle the relations among managers, operators, residents and tourists in terms of interest, form a sustainable, block tourism development-oriented and culture-protected operating mechanism.

Table 1. Transformation mode for historical block heritages

\begin{tabular}{|l|l|}
\hline $\begin{array}{l}\text { Important historic buildings, public buildings in } \\
\text { the block }\end{array}$ & Tourist attractions, history and culture museum \\
Traditional commercial facilities and & Characteristic commercial street for tourism, \\
commercial heritage & famous tourism brand shop \\
Characteristic residential buildings & Residence museum, high-end reception \\
& facilities \\
General residential buildings & Mass reception service facilities \\
Important intangible cultural heritage & ICH museum, high-end tourism products, \\
& special performances \\
Common intangible cultural heritage & Special tourism products, special performances \\
\hline
\end{tabular}

\section{Tourism development pattern based on historical block heritage restoration}

It is necessary to restore the important historical landmarks and appendages of the block, reconstruct the important historical places for activities of festivals, carry on the creative protection on the historical sites of the blocks, combine the historical culture of the block with the creative tourism, and show the historical culture of the block in a creative way and construct the landmark-based attraction of the cultural tourism of the block through the transformation of the historical block system. Through the display of historical and cultural elements, the sense of history and recognition of the block can be increased and the urban brand recognition can be promoted.

\section{Analysis on the development pattern based on the transformation from traditional commercial block to the tourism commercial block}

In a traditional block relying on bustling commercial format where has a good turnover of goods, a convenience of material turnover, a strong business culture atmosphere, traditional handicraft characteristics and a large number of well-known commercial brands, such block features are important for attracting tourists.

The development of tourism products in such historical and cultural blocks is embodied in three aspects:

First, the development of the commercial cultural potential of such cultural block. It is important to design the historical block tourism products, show the tourism characteristics of the historical and cultural blocks, build the unique tourism quality of the block, and reflect the unique humanistic landscape and profound historical and cultural connotations.

Second, the development of historical and cultural block tourism industry. Through the creation of unique tourism products, it can use specific tourism projects to develop urban economy, so as to reflect the economic value of the historical and cultural blocks.

Third, by virtue of the economic value of the historical block, it can increase its social value, increase the employment and income of residents and promote social stability.

In accordance with the principle of "restoring it to the historical image as it was", the original 
style of the blocks should be protected in accordance with the historical image as it was. It can introduce some new projects under the premise of being in line with the historical and cultural atmosphere, and can make full use of commercial heritage resources, such as old brands and folk skills in the blocks, so as to restore the prosperous and flourishing scene of Qinghe Lane, revitalize the old shops and some folk skills. With the passage of time, the stone houses even with the erosion of winds and rains are shown in Figure 1, and lodges full of ethnic culture are shown in Figure 2.

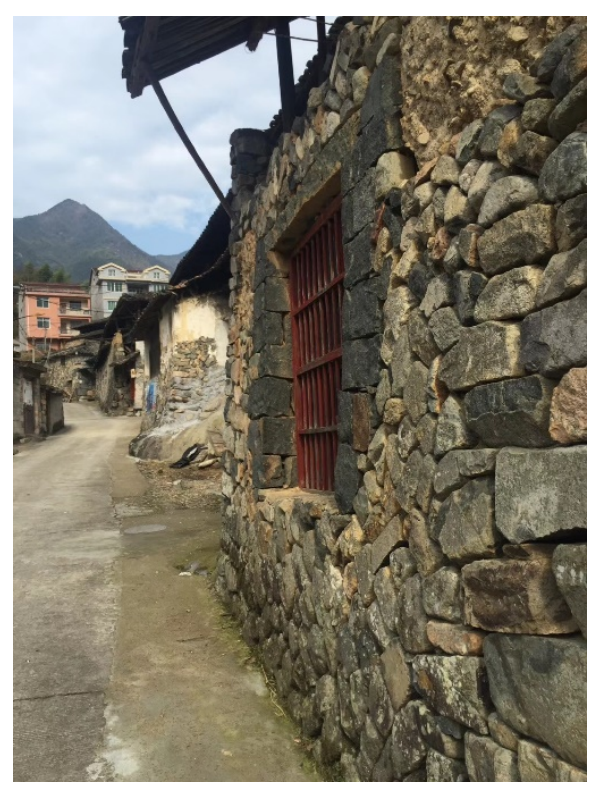

Fig. 1 The stone houses even with the erosion of winds and rains

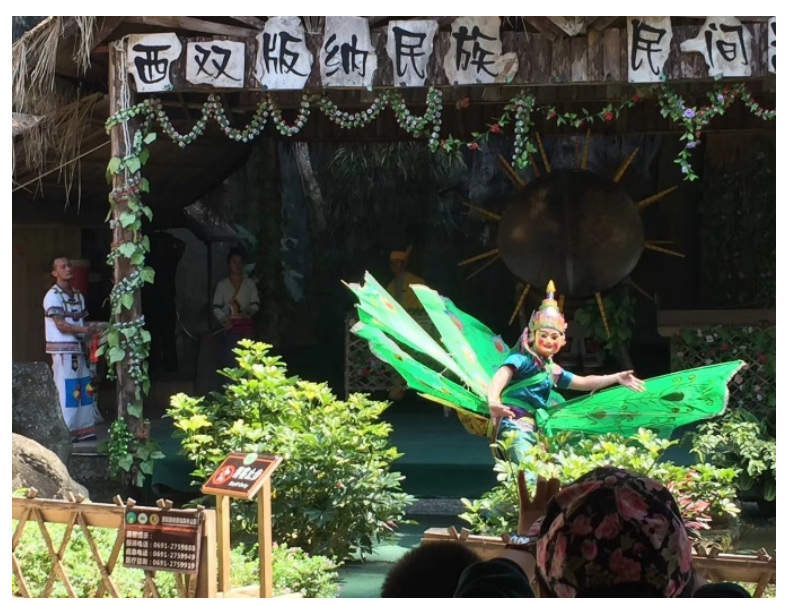

Fig. 2 Lodges full of ethnic culture

The trade format revolves around the theme of the block culture, especially the main merchants in the block, which should have obvious cultural individuality and themes and pay attention to the combination of the attraction format and the consumption format. At the format level, in leisure-type commercial streets, middle and high end formats should be dominant, so as to pay attention to the emotional experience of consumers and highlight the unique cultural individuality and theme characteristics. The "catering plus shopping"-dominated lodge development pattern is shown in Figure 3.

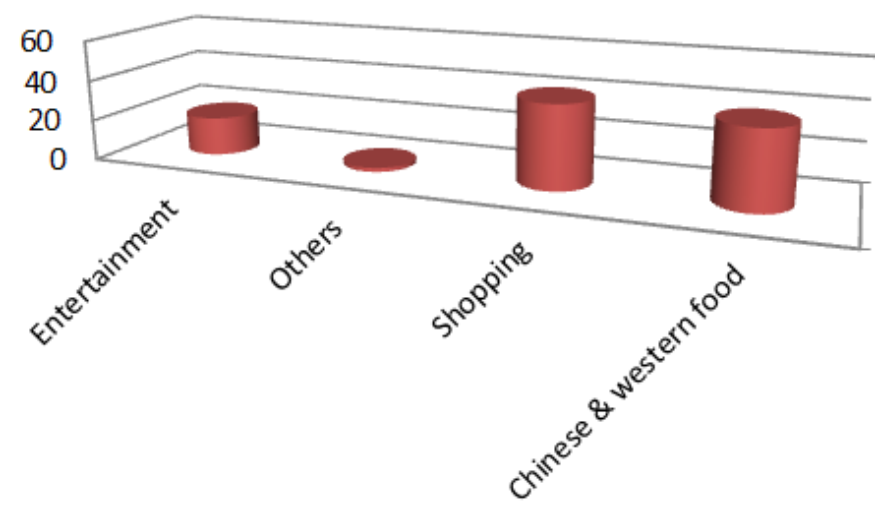

Fig. 3 "Catering plus shopping"-dominated lodge

The catering, lodging and shopping lodge development pattern based on courtyard scene is 
shown in Figure 4.

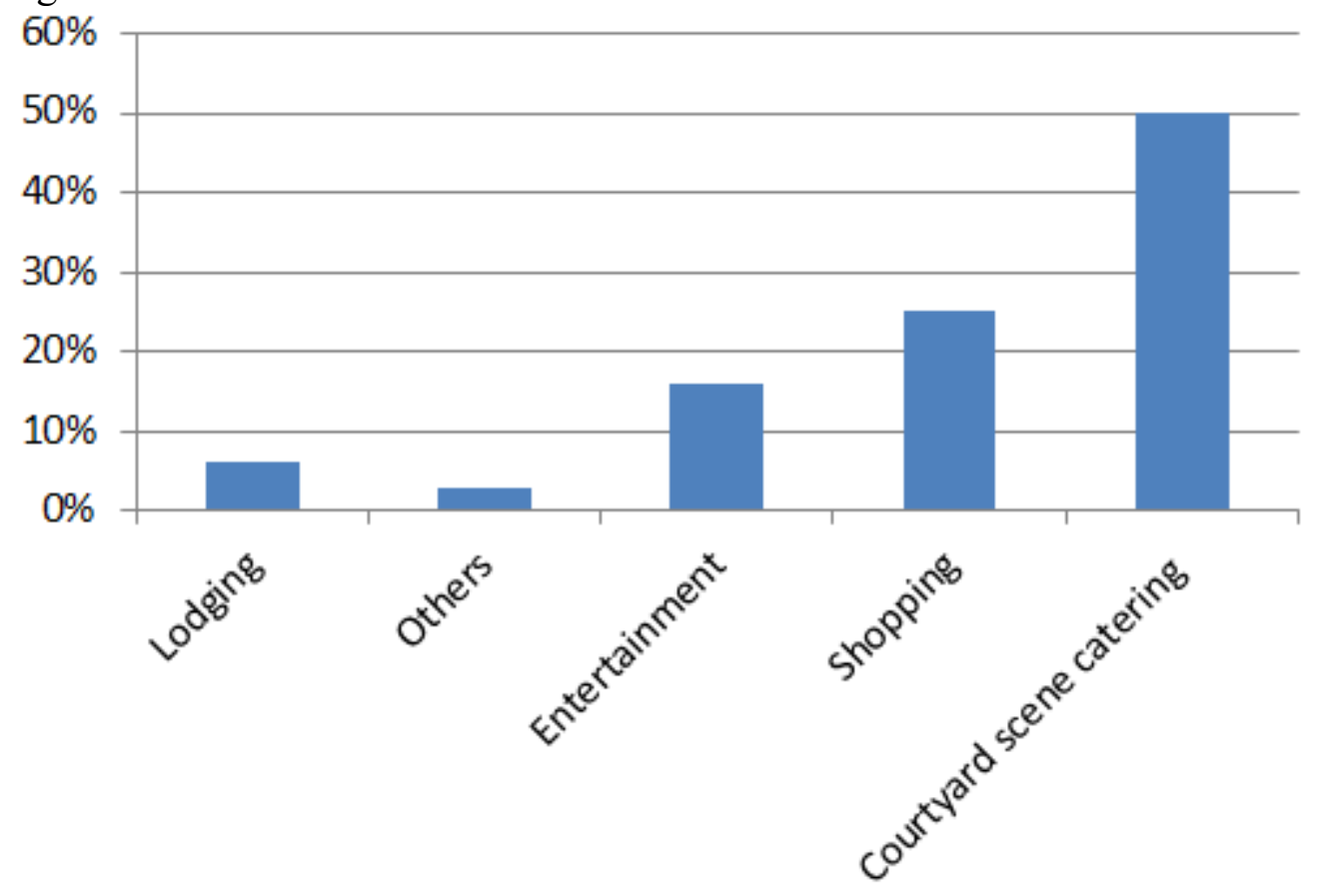

Fig. 4 Courtyard scene style

The theme positioning of different commercial blocks has its own characteristics, and the main basis is: urban culture, regional folk culture and the related historical culture. Different cities mainly choose local city culture and regional folklore with high representative nature to form a characteristic, while the leisure theme choices in the same block should be diverse. The lodge development pattern based on bar entertainment, retail, teahouse and catering is as shown in Figure 5 .

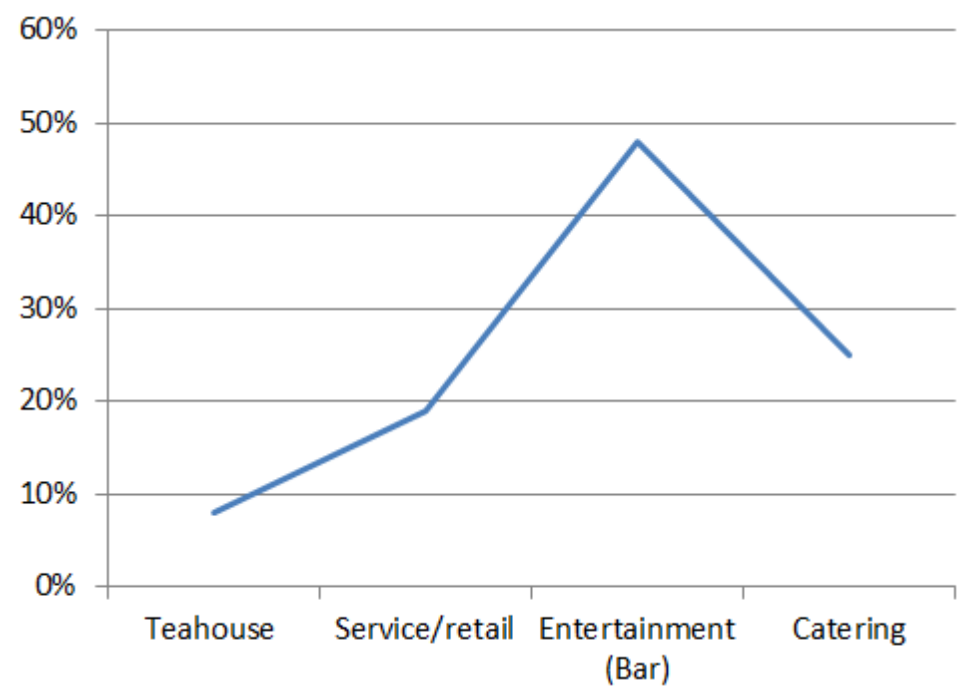

Fig. 5 Bar entertainment-dominated lodge

The lodge development pattern based on sightseeing streets is shown in Figure 6 . 


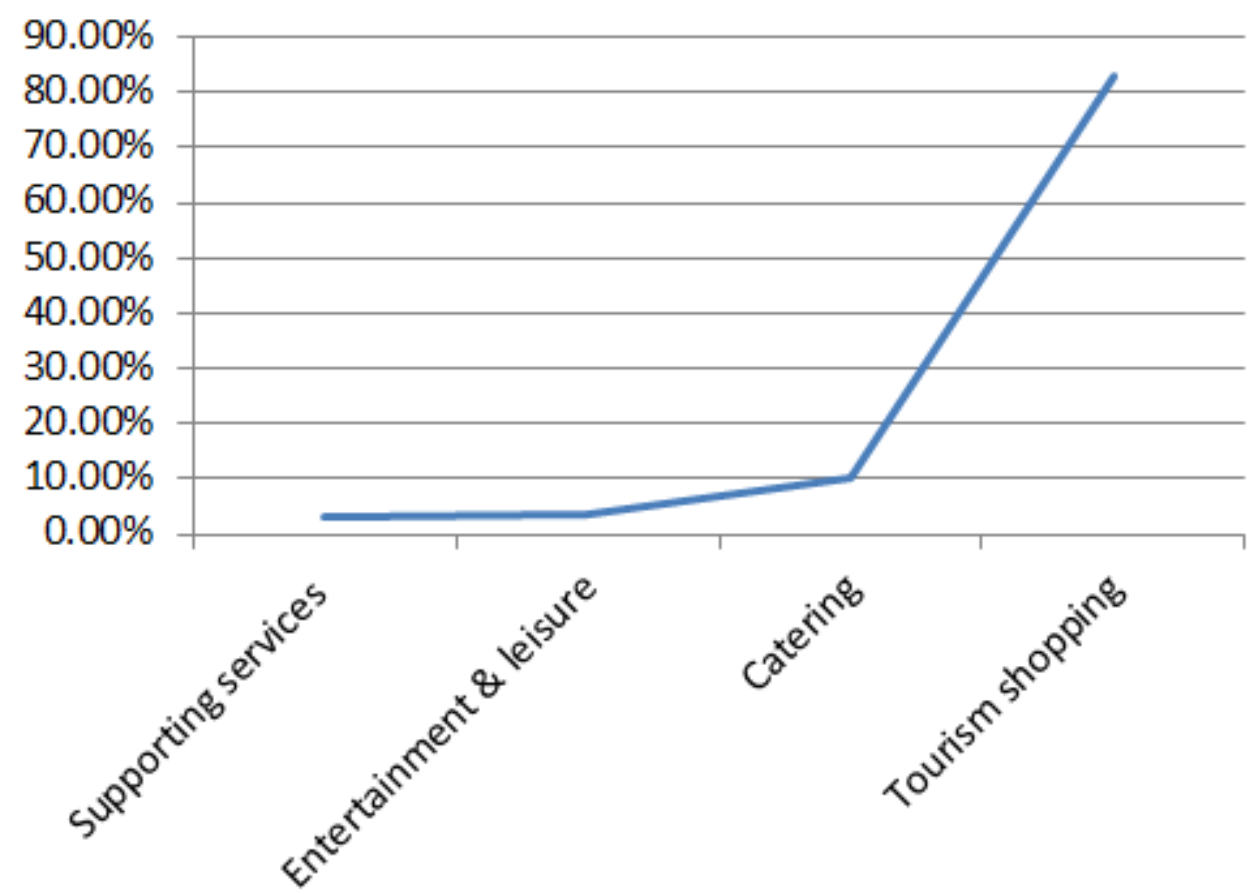

Fig. 6 Sightseeing streets-dominated lodge

The exploration and application of regional culture, and the integration of them into the catering, shopping, accommodation and other formats are conducive to forming a business theme with unique attraction. It needs to fully release the tourism value of the city's commercial heritage, and transform it into a tourism product that can be appreciated, enjoyed and purchased.

Taking the renovation of the blocks in Wenzhou's Wutian Old Street as an example, it has paid attention to the protection and inheritance of historical buildings and emphasized the connotation and cultural expression of the landscape. In the case of Wenzhou's Wutian Old Street, the stone buildings were a special feature and the old houses were transformed into multi-functional, fashionable and leisure culture-dominated entertainment centers with the formats of catering, shopping and performance arts, as shown in Figure 7.

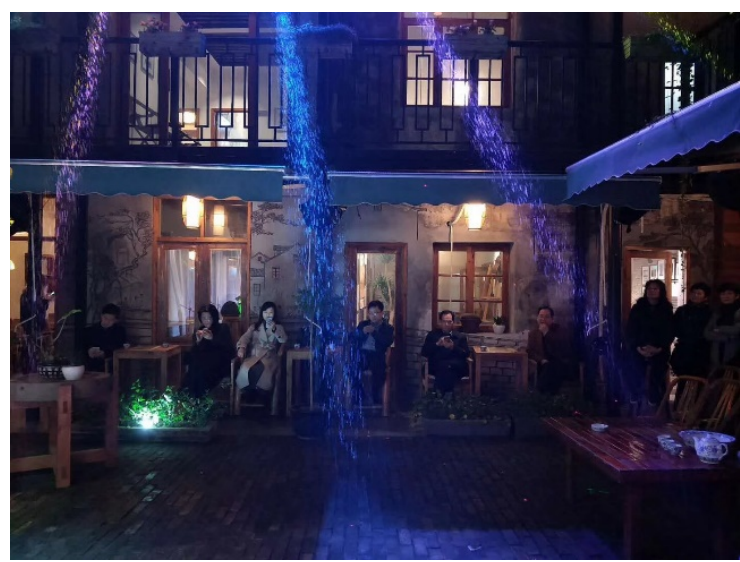

Fig. 7 Renovation of Wenzhou's Wutian Old Street

The main investment bodies should be led by governments or enterprises. The enterprise-leading investment model conforms to the market development trend and is conducive to standardizing the 
management of the block.

\section{Conclusion}

In the development of the historical blocks, the decisions should be made based on the commercial formats, the present situation of cultural protection and tourism development in these blocks, the consumption preference of the consumers and the commercial development environment of the historical streets. It also needs to figure out and seize the opportunities and standpoints for seeking commercial format upgrading and tourism development in these blocks. By taking the area with unique style as the core, it can convert some blocks into a municipal-level ecological interval belt pilot with the functions of protecting the original ecological feature, enjoying the leisure of ancient towns, cultural experience, ecological residences and countryside recreation.

\section{Acknowledgements}

2018 Zhejiang Province philosophy and social science planning (18NDJC133YB)

\section{References}

[1] Chen Fenling. Economic Situation and the Possibility of Constructing Local Culture Industries in Aboriginal Tribes: a Case Study of Taoyuan, Hsinchu and Miaoli Areas[J]. Journal of State and Society, 2008(4): 1-42.

[2] Shi Qingren, HUANG Shi-hui. The Creative Strategy for Urban and Rural Governance: Take Ping-Tung NGO's Creative Activities as an Example[J]. The Journal of Ping-Tung History, 2014(18): 45- 106.

[3] Wu Mingru. An Exploratory Study of Empowerment Mechanisms for Vulnerable Communities: Three Kinds of CSW Model Analysis[J]. Taiwan Community Work and Research Association, 2013, 3(3): 1—58.

[4] Li Yijun, Liu Chengxian. The Action Research of Community Empowerment through Community Program[J]. Taiwan Community Work and Research Association, 2013, 3(3): 59-97.

[5] Wu Mingru. The dilemma of the Administration for Community Evaluation. The 2006 Community Performance-Related Evaluation Report in Taiwan and Southern Fujian[C]. Ministry of the Interior, 2006. 